\title{
The promise of a cognitive perspective on jury deliberation
}

\author{
Jessica M. Salerno \\ University of Illinois, Chicago, Illinois \\ and American Bar Foundation, Chicago, Illinois \\ AND \\ Shari SeIdMan Diamond \\ Northwestern University, Evanston, Illinois \\ and American Bar Foundation, Chicago, Illinois
}

\begin{abstract}
Despite much psychological research regarding jury decision making, surprisingly little is known about the deliberation process that gives rise to jury verdicts. We review classic jury decision-making research regarding the importance of deliberation and more recent research, investigating deliberation and hung juries, that challenges the view that deliberation does not have an important impact on verdicts. We advocate greater attention to potential cognitive processes during deliberation that might explain the transition between predeliberation preferences and a jury's ultimate verdict. We then review cognitive work in the group context generally, and the jury context specifically, illustrating the promise of a cognitive perspective on jury deliberation. Finally, we identify cognitive phenomena likely to be particularly valuable in illuminating deliberation behavior.
\end{abstract}

Psychologists have learned a great deal about juries from research conducted over the past 50 years. Much of that research has directly contradicted claims made by courts about jury functioning. For example, writing for a plurality of the United States Supreme Court in Johnson v. Louisiana (1972), Justice White concluded that a unanimous decision rule was not required because a "majority will cease discussion and outvote a minority only after reasoned discussion has ceased to have persuasive effect or to serve any other purpose." In contrast, empirical research has shown that a nonunanimous decision rule can undermine attention to minority arguments (Diamond, Rose, \& Murphy, 2006; Nemeth, 1977; Saks, 1977). Although some courts do not embrace research findings from psychological research on the jury, other courts welcome them. For example, evidence on the way jurors use the opportunity to submit questions for witnesses during trial helped to persuade the court in S.E.C. v. Koenig (2009) of the benefits of approving that procedure (Diamond, Rose, Murphy, \& Smith, 2006).

Although many advances have been made in understanding jury deliberations, several important questions remain that cognitive psychology is in a strong position to address. We know that the distribution of individual jurors' predeliberation verdict preferences is a strong predictor of the jury's final verdict, but not what makes the majority position so influential or the circumstances under which minorities are likely to prevail. Are majorities influential because minority jurors simply succumb to normative influence or because of vote changes resulting from cognitive restructuring or group-level cognitive processes (e.g., memory pooling and error correction)? What happens differently during deliberations when a jury is hung or a minority convinces the majority to change their vote?

These unanswered questions call for the investigation of the role played by cognitive constructs, such as recall for testimony, memory pooling, error checking, collaborative false recall, and heuristics. Thus, we call for cognitive psychologists to broaden their inquiry from the topic of individual jurors to that of the deliberation process. We begin by briefly reviewing what psychologists have learned about the deliberation process. We then describe a set of remaining questions that would benefit from cognitive psychologists' attention.

\section{Research on Jury Decision Making: \\ The Production of Verdicts}

Jury decision-making research began in the 1950s with the Chicago Jury Project. In their landmark field study, Kalven and Zeisel (1966) conducted a judicial survey that covered 3,500 criminal jury trials. In each case, the trial judge described the characteristics of the case, the jury's verdict, and how the judge would have decided the same case in a bench trial. By analyzing the case characteristics associated with agreement and disagreement between the judge and jury, Kalven and Zeisel attempted to map the 
determinants of jury decisions. Although properly hailed as innovative and emulated by later researchers, Kalven and Zeisel recognized the potential limits of relying on judicial reports and considered whether they had "studied the wrong thing" (p. 474) by ignoring the potential role of deliberations. For evidence that they had not missed something of importance, they relied on a set of $225 \mathrm{ju}-$ rors' postdeliberation retrospective reports of the number of the jury's guilty votes on the first ballot and the final jury verdict. Because a majority vote on the first ballot predicted the jury's verdict in $90 \%$ of the cases, Kalven and Zeisel opined that important events did not occur during deliberations, providing later researchers with a welcome justification for dispensing with the arduous and costly process of obtaining and analyzing group deliberation data. Even though Kalven and Zeisel explicitly recognized its tentative character, calling it a "radical hunch," their metaphor-that the deliberation process is like a developer that brings out the picture from exposed film-caught on.

More recent work on the jury, however, raises questions about the power of that "hunch." A significant weakness in using retrospective reports of first votes to estimate the transition from predeliberation voting to verdict is that jurors do not generally take an immediate anonymous vote at the beginning of their deliberations, the only procedure that would reveal independent and truly "predeliberation" vote preferences. Although a juror often suggests taking an early vote, discussion typically interrupts or derails completion of the vote as jurors raise questions about the interpretation of the evidence (Diamond \& Casper, 1992). Even when jurors do take an immediate initial vote by, for example, going around the table, the expressed verdict preferences of those voting first can influence those who vote later (Davis, Stasson, Ono, \& Zimmerman, 1988). Most importantly, if any deliberations precede the initial vote, that first vote will not reveal any changes in position that occurred during deliberations before the vote was taken, thereby underestimating the impact of deliberations. The most ecologically valid simulation studies of jury deliberations reveal that immediate votes are the exception, rather than the rule (e.g., Diamond \& Casper, 1992 [21\% of juries]; Hastie, Penrod, \& Pennington, 1983 [28\% of juries]). Posttrial surveys of real jurors have produced rates that range from 3\% (Sandys \& Dillehay, 1995) to $31 \%$ (Devine et al., 2004). In the Arizona Filming Project, in which the researchers were able to view actual deliberations in 50 civil cases, only $20 \%$ of the juries took a vote within the first $10 \mathrm{~min}$ of deliberations (Diamond, Vidmar, Rose, Ellis, \& Murphy, 2003). Moreover, the Arizona juries tended to delay voting precisely when deliberations were likely to be most influential: The longer the trial, the longer jurors discussed the evidence before taking an initial vote $(r=.54)$.

Although jurors do tend to form opinions and construct plausible accounts in the course of a trial (Hastie, 1993), their views can be tentative as deliberations begin. In posttrial interviews, $20 \%$ of real jurors from 382 criminal trials indicated that leaning toward one side did not occur until during the jury's deliberations (Hannaford-Agor,
Hans, Mott, \& Munsterman, 2002). They were also asked to indicate which side they favored before deliberations, on a 7-point scale. Over one third (38\%) selected 3, 4, or 5 , with $17 \%$ of them choosing 4 , the midpoint of the scale. Although these reports might be somewhat inflated by the jurors' desire to report behavior consistent with the court's admonition to avoid reaching conclusions before the end of the trial, a lack of strong leaning or certainty at the beginning of deliberations by a substantial percentage of jurors leaves ample room for deliberations to play a crucial role in jurors' verdict preferences.

The strongest evidence that the initial distribution of views on the jury trumps the impact of deliberation has come from a series of simulation studies. For example, Davis, Kerr, Atkin, Holt, and Meek (1975) compared predeliberation verdict preferences with jury verdicts reached after deliberations. They found that the best-fitting model for transforming predeliberation preferences to final verdicts predicted that if two thirds of the initial preferences favor a verdict, the jury would adopt that verdict; otherwise, the deliberation would end with a hung jury. A recent review of jury simulations, however, concluded that when no more than three fourths of a jury's initial preferences favored a verdict, $31 \%$ ended with a hung jury (Devine, Clayton, Dunford, Seying, \& Pryce, 2001). A major problem for drawing conclusions from these laboratory studies is that deliberations in the laboratory are generally conducted under severe time constraints, resulting in high rates of hung juries. The hung jury rate across all of the studies reviewed by Devine et al. (2001) was 21\%, whereas outside the laboratory, the hung jury rate is typically under $10 \%$. Thus, we have no way of knowing how often the predeliberation majority position would have prevailed, because the juries were cut off prematurely. Finally, the act of committing to a verdict before deliberation, even privately, may influence how jurors behave during deliberations. Individuals advocated riskier behavior after group discussion more often when they had (vs. had not) committed, albeit privately, to a position before group discussion began (Castore, 1972). Even without taking into account these methodological issues, Devine et al. (2001) concluded, on the basis of the verdict pattern, that the critical threshold for conviction is "somewhat higher than two thirds" (p. 692), delineating a large potential role for the impact of jury deliberations on the many juries that begin with a more divided initial split.

Moreover, in research examining more complex jury decisions (i.e., beyond a dichotomous verdict), results have revealed verdict patterns that did not mechanically reflect the predeliberation average or majority verdict preference. The modal verdict preference of juries with a choice of four verdicts in a homicide trial was not the most frequent individual predeliberation verdict preference, although it was the verdict preferred by a set of legal experts (Hastie et al., 1983). Juries' postdeliberation monetary awards are typically higher than predeliberation awards when deciding compensation for intentional acts, such as antitrust damage awards in a price-fixing case (Diamond \& Casper, 1992) and punitive awards (Schkade, Sunstein, \& Kahneman, 2000). For example, as jurors discussed evidence in a 
price-fixing case, they tended to see the behavior as more damaging. The median predeliberation damage award was strongly correlated with the jury's award, but the average damage awards of the juries were $27 \%$ higher than the average predeliberation awards (Diamond \& Casper, 1992). Kaplan and Miller (1987), however, found this inflation effect of deliberation for punitive, but not for compensatory, awards. Finally, a leniency bias stemming from the beyond a reasonable doubt standard might emerge during deliberations in criminal cases: Jurors favoring an acquittal are more likely to influence the jury's verdict when the jury is close to evenly divided (MacCoun \& Kerr, 1988; but see Devine et al., 2004, which showed no evidence of a leniency effect based in real jurors' retrospective reports). These examples of the disconnect between predeliberation preferences and final jury decisions again point to the potential for deliberations to have an impact on final outcomes.

Finally, another set of studies has revealed effects that emerge only following deliberations, suggesting that reliance on predeliberation judgments as proxies for postdeliberation verdicts can be misleading. For example, some studies have shown that jury instructions have a greater effect on postdeliberation than on predeliberation comprehension of instructions (e.g., Diamond \& Levi, 1996) and verdicts (e.g., Kerwin \& Shaffer, 1994; Wheatmann \& Shaffer, 2001). Two studies have shown that the presence versus absence of cross-examination significantly affected jurors' case judgments only after deliberation (Salerno \& McCauley, 2009; Spanos, Dubreuil, \& Gwynn, 1991). Having an adversarial versus court-appointed expert significantly affected predeliberation, but not postdeliberation, juror judgments (Brekke, Enko, Clavet, \& Seelau, 1991). Thus, disregarding the jury process in these studies would have led to misleading conclusions.

\section{Research on Jury Decision Making: The Hung Jury}

The deliberation process is also implicated when the jury fails to reach a verdict. An important question is whether a single recalcitrant and obstructionist juror is responsible for the hung jury, or whether the failure to reach agreement can be traced to more reasoned disagreement. In a survey of jurors in 382 criminal cases, $85 \%$ of the hung juries had at least three jurors who disagreed with the majority's opinion (Hannaford-Agor et al., 2002). Moreover, jurors who served on juries that ended in a deadlock rated the trial evidence as significantly more ambiguous (i.e., less favorable to either side) than did jurors who served on juries that reached a verdict.

Diamond, Rose, and Murphy (2006) also identified cognitive sources for disagreement within juries in a jurisdiction that permitted nonunanimous verdicts. They compared the positions of the holdout jurors (i.e., the jurors who did not go along with the majority in a jurisdiction that required agreement from three fourths of the jury for a verdict) to the verdicts preferred by the judges in those cases. The judge sided with the majority eight times (57\%) but sided with the holdouts six times (42\%). Thus, deliberation can have an important effect; it provides the opportunity for minority jurors to convince the majority or to hang the jury when the evidence is close enough to undermine agreement on the appropriate verdict. This suggests an active deliberation process that results in verdicts consistent with the majority only when this process convinces the minority jurors. If an education process typically moves a jury toward consensus, why and when does it run aground? One innovative jury procedure enacted in Arizona assumes that cognitive obstacles are likely to be responsible for leading juries to an impasse (Arizona Rule of Criminal Procedure, $\S 22.4,2007$ ). If the jury tells the judge that it cannot reach agreement, the judge can ask the jurors to identify the issues that continue to divide them and may then offer assistance through additional instructions, further argument, or even further evidence (Dann, 1993). Cognitive psychologists clearly could add insights that might guide this dialogue between the judge and jury.

This review of research on the effects of jury deliberations thus highlights mixed results, but suggests that deliberations can be quite influential. What is needed is an analysis of the processes that occur during jury deliberation and why and under what conditions deliberations are likely to matter. It is here that cognitive psychologists have great potential to contribute. We next review promising cognitive group decision-making work relevant to the jury deliberation process and make suggestions for future applications of cognitive concepts to jury deliberation.

\section{Cognitive Psychology and \\ Group Decision-Making Research}

Cognitive studies of group decision making have already contributed insights relevant to the deliberation process. Comparisons between the performance of groups and individuals on cognitive tasks speak to the classic jury decision-making question of whether group verdicts are a product of actual collaboration between jurors or merely a pooling of prediscussion preferences. For example, Clark, Hori, Puthnam, and Martin (2000) compared noncollaborative resource pooling and collaboration, finding that although a group advantage can be obtained merely by deferring to the majority, resource pooling on its own cannot explain the group advantage in item and associative recognition memory. This challenges the view of jury decision making that characterizes verdicts as a product of pooling prediscussion preferences and going with the majority.

Group recall. A number of studies addressing group recall are relevant to understanding jury deliberation processes. Although recall by collaborative groups is better than recall by individuals (Maki, Weigold, \& Arellano, 2008), collaborative groups demonstrate diminished recall performance, as compared with noninteracting groups, in terms of fewer words recalled (Basden, Basden, Bryner, \& Thomas, 1997; Maki et al., 2008; Weldon, Blair, \& Huebsch, 2000) - a phenomenon referred to as collaborative inhibition - and greater false word recognition (Thorley \& Dewhurst, 2009). These results challenge some claims about the benefits of deliberation. Furthermore, cognitive psychologists have investigated inaccuracies exhibited by eyewitnesses (e.g., Eakin, Schreiber, \& Sergent-Marshall, 2003; Loftus, 1975). If one thinks of a 
juror as an eyewitness to testimony in a court, jurors might also exhibit these inaccuracies during deliberation. Incorrect responses supplied by confederate group members during memory tasks can influence other group members' memory, particularly when (1) the stimulus is less likely to be remembered (Walther et al., 2002), (2) there are no dissenters (Walther et al., 2002), (3) participants are under pressure to perform well (Reysen, 2003; Thorley \& Dewhurst, 2007), or (4) group size decreases (Thorley \& Dewhurst, 2007).

These findings from the cognitive perspective provide valuable insights into how the deliberation process might affect individual jurors' recall for evidence and suggest potential candidates for jury reform. The challenge is to design procedures and instructions that might ameliorate collaborative inhibition or the impact of false recollections when they occur within a jury. For example, if group pressure to offer comments causes jurors with poorer recall to share inaccurate memories with the group, the frequent suggestion that all jurors should contribute during deliberations may have the counterproductive effect of fostering false recall.

Although the cognitive work on group recall has potential implications for jury decision making, the tasks utilized differ in important ways from the task a jury faces. In a trial, the credibility of evidence varies, and the various pieces of evidence are interrelated. Furthermore, many of the cognitive group studies have used either perceived group members or real group members who did not interact (i.e., communication via computer, with no direct contact). Investigating questions about group recall in a more ecologically valid jury environment would be a useful next step. Moreover, recall is only the first step in the jury decision-making process. Jurors also have to process, integrate, reconcile, and reason about the other jurors' recollections of the testimony. Cognitive psychology can contribute to characterizing the process through which jurors integrate each others' recall about the testimony into one story.

Other cognitive processes. Researchers have begun to investigate other cognitive phenomena in a group context, including planning and strategizing (Knoblich \& Jordan, 2003), heuristic processing (Hertel, Neuhof, Theuer, \& Kerr, 2000; Reimer \& Katsikopoulos, 2004), cooperation (Hertel et al., 2000), information pooling (Ohtsubo, 2005), and learning (Willoughby, Wood, McDermott, \& McLaren, 2000). Again, these concepts are highly relevant but difficult to generalize to jury decision making. For example, prior research has shown evidence of individual jurors engaging in heuristic processing; cognitive psychologists' investigation of heuristic processing in groups could easily be tested in the jury context.

\section{Cognitive Psychology and Jury Decision-Making Research}

A few psychologists have begun to take a cognitive perspective on jury deliberation, focusing on how elements of the trial process, such as deliberation (Pritchard \& Keenan, 2002), pretrial publicity (Ruva, McEvoy, \& Bryant, 2007), and allowing juror note taking (ForsterLee,
Kent, \& Horowitz, 2005), affect jurors' memory. For example, Pritchard and Keenan found that deliberation led to slight memory improvements through error checking, without distorting case facts. Yet the jurors were not sensitive to the accuracy of their memories, suggesting that there may be limitations in the ability of deliberations to produce memory improvements. This cognitive perspective on jury deliberation revealed insight into the process through which individual jurors' opinions are transformed into a final verdict.

\section{New Frontiers for Understanding Juries With Cognitive Research}

Many topics in cognitive psychology relevant to jury decision making that have, to this point, been examined primarily in individuals could be investigated by cognitive psychologists at the group level. Many studies have shown how heuristics such as anchoring, framing, and the hindsight bias affect judgments about legal questions by both laypersons and judges (e.g., Chapman \& Bornstein, 1996; Englich \& Mussweiler, 2001; Guthrie, Rachlinski, $\&$ Wistrich, 2001). Yet we know little about how group discussion affects the influence of those heuristics. Cognitive psychologists could also investigate how jurors are influenced by fellow jurors who bring up forbidden topics. The real jurors from the Arizona Jury Project discussed forbidden topics (i.e., insurance) during deliberation, but in more than half of the cases in which a juror raised the issue of insurance, at least one juror tried to redirect the discussion away from the forbidden topic (Diamond \& Vidmar, 2001). Are jurors' impressions of a case cognitively influenced by these references to forbidden topics, even if another juror attempts to redirect the conversation? Cognitive psychologists could extend these lines of research by investigating how jurors respond to and are influenced by heuristic-based reasoning or mentions of inadmissible testimony from other jurors during deliberations.

Similarly, we know that witness confidence affects jurors' credibility assessments and that the effect depends on other evidence of the accuracy of the witness (Spellman \& Tenney, 2010; Tenney, MacCoun, Spellman, \& Hastie, 2007). Jurors judge an accurate witness as more credible if he or she displays high (vs. low) confidence but an inaccurate witness as less credible if he or she displays high (vs. low) confidence (even though the inaccuracy is about a peripheral detail). These results suggest that jurors have a preference for witnesses with good calibration (i.e., are confident when accurate, but not confident when inaccurate; Tenney et al., 2007). During deliberation, jurors (like witnesses during trials) vary in how confidently they express their positions, and fellow jurors can directly evaluate their accuracy in recalling evidence. Do the jurors have a similar calibration sensitivity to what other jurors claim about their prior experiences or knowledge? Cognitive psychologists could fruitfully investigate whether group deliberations mirror or modify the calibration effect.

Other cognitive themes offer a similar potential. How do individual jurors' different anchors influence the group's eventual damages conclusion? How do individual jurors' different reconstructions of a trial "story" become 
integrated into one group conclusion? What roles do analogical reasoning and memory pooling play during deliberations as jurors struggle to apply a difficult instruction on the law? When variables have a different effect after jurors deliberate, through what process do these variables become more or less influential?

\section{Conclusion}

Much jury decision-making research challenges the popular and convenient conclusion that the deliberation process is not important. This review of limitations in the classic work that spawned this conclusion, along with studies investigating the deliberation process itself, and hung juries specifically, reveals that there is much room for the deliberation process to have an impact on jury verdicts. What remains unclear is the nature of this impact. Cognitive research about group decision making in general and about juries in particular demonstrates the promise of a cognitive perspective. Remaining questions about the processes through which individual opinions are transformed into jury verdicts or the majority fails to convince the minority require an investigation of cognitive concepts, such as recall, information pooling, error correction, analogical reasoning, heuristics, and perceptions of fellow jurors' confidence-accuracy calibrations. The further application of these and other cognitive concepts to the processes of jury deliberation holds promise not only for understanding jury decision making, but also for informing jury reform efforts.

\section{AUTHOR NOTE}

Correspondence concerning this article should be addressed to S. S. Diamond, School of Law, Northwestern University, 375 E. Chicago Ave., Chicago, IL 60611 (e-mail: s-diamond@law.northwestern.edu).

\section{REFERENCES}

Arizona Rule of Criminal Procedure $\$ 22.4$ (2007).

Basden, B. H., Basden, D. R., Bryner, S., \& Thomas, R. L. (1997). A comparison of group and individual remembering: Does collaboration disrupt retrieval strategies? Journal of Experimental Psychology: Learning, Memory, \& Cognition, 23, 1176-1189.

Brekke, N. J., Enko, P. J., Clavet, G., \& Seelau, E. (1991). Of juries and court-appointed experts: The impact of nonadversarial versus adversarial expert testimony. Law \& Human Behavior, 15, 451-475.

CAstore, C. H. (1972). Group discussion and prediscussion assessment of preferences in the risky shift. Journal of Experimental Social Psychology, 8, 161-167.

Chapman, G., \& Bornstein, B. H. (1996). The more you ask for the more you get: Anchoring in personal injury verdicts. Applied Cognitive Psychology, 10, 519-540.

Clark, S. E., Hori, A., Puthnam, A., \& Martin, T. P. (2000). Group collaboration in recognition memory. Journal of Experimental Psychology: Learning, Memory, \& Cognition, 26, 1578-1588.

DANN, B. M. (1993). "Learning lessons" and "speaking rights": Creating educated and democratic juries. Indiana Law Journal, 68, 1229-1279.

Davis, J. H., KerR, N. L., Atkin, R. S., Holt, R., \& Meek, D. (1975) The decision processes of 6- and 12-person mock juries assigned unanimous and two-thirds majority rules. Journal of Personality \& Social Psychology, 32, 1-14.

Davis, J. H., Stasson, M. F., Ono, K., \& Zimmerman, S. (1988). Effects of straw polls on group decision making: Sequential voting pattern, timing, and local majorities. Journal of Personality \& Social Psychology, 55, 918-926.

Devine, D. J., Clayton, L. D., Dunford, B. B., Seying, R., \& Pryce, J.
(2001). Jury decision making: 45 years of empirical research on deliberating groups. Psychology, Public Policy, \& Law, 7, 622-727.

Devine, D. J., Olafson, K. M., Jarvis, L. L., Bott, J. P., Clayton, L. D., \& WoLfE, J. M. T. (2004). Explaining jury verdicts: Is leniency bias for real? Journal of Applied Social Psychology, 34, 2069-2098.

DiAMOND, S. S., \& CASPER, J. D. (1992). Blindfolding the jury to verdict consequences: Damages, experts, and the civil jury. Law \& Society Review, 26, 513-557.

Diamond, S. S., \& Levi, J. N. (1996). Improving decisions on death by revising and testing jury instructions. Judicature, 79, 224-232.

Diamond, S. S., Rose, M. R., \& Murphy, B. (2006). Revisiting the unanimity requirement: The behavior of the non-unanimous civil jury. Northwestern University Law Review, 100, 201-230.

Diamond, S. S., Rose, M. R., Murphy, B., \& Smith, S. (2006). Juror questions during trial: A window into juror thinking. Vanderbilt Law Review, 59, 1927-1972.

DiAmond, S. S., \& VIDMAR, N. (2001). Jury room ruminations on forbidden topics. Virginia Law Review, 87, 1857-1915.

Diamond, S. S., Vidmar, N., Rose, M. R., Ellis, L., \& Murphy, B. (2003). Jury discussions during civil trials: Studying an Arizona innovation. University of Arizona Law Review, 45, 1-81.

Eakin, D. K., Schreiber, T. A., \& Sergent-Marshall, S. (2003). Misinformation effects in eyewitness memory: The presence and absence of memory impairment as a function of warning and misinformation accessibility. Journal of Experimental Psychology: Learning, Memory, \& Cognition, 29, 813-825.

ENGLich, B., \& Mussweiler, T. (2001). Sentencing under uncertainty: Anchoring effects in the courtroom. Applied Social Psychology, 31, 1535-1551.

ForsterLee, L., Kent, L., \& Horowitz, I. A. (2005). The cognitive effects of jury aids on decision-making in complex civil litigation. Applied Cognitive Psychology, 19, 867-884.

Guthrie, C., Rachlinski, J. J., \& Wistrich, A. J. (2001). Inside the judicial mind. Cornell Law Review, 86, 777-830.

Hannaford-Agor, P. L., Hans, V. P., Mott, N. L., \& Munsterman, G. T. (2002). Are hung juries a problem? Retrieved from The National Center for State Courts: www.ncsconline.org/WC/Publications Res_Juries_HungJuriesProblemPub.pdf.

Hastie, R. (ED.) (1993). Inside the juror: The psychology of juror decision making. New York: Cambridge University Press.

Hastie, R., Penrod, S. D., \& Pennington, N. (1983). Inside the jury. Cambridge, MA: Harvard University Press.

Hertel, G., Neuhof, J., Theuer, T., \& Kerr, N. L. (2000). Mood effects on cooperation in small groups: Does positive mood simply lead to more cooperation? Cognition \& Emotion, 14, 441-472.

JOHNSON V. LOUISIANA, 406 U. S. 356 (1972).

Kalven, H., \& ZeIsel, H. (1966). The American jury. Chicago: University of Chicago Press.

KaPLAN, M. F., \& MilLeR, L. E. (1987). Group decision making and normative versus informational influence: Effects of type of issue and assigned decision rule. Journal of Personality \& Social Psychology, 53, 306-313

Kerwin, J., \& Shaffer, D. R. (1994). Mock jurors versus mock juries: The role of deliberations in reactions to inadmissible testimony. Personality \& Social Psychology Bulletin, 20, 153-162.

KNOBLICH, G., \& JoRDAN, J. S. (2003). Action coordination in groups and individuals: Learning anticipatory control. Journal of Experimental Psychology: Learning, Memory, \& Cognition, 29, 1006-1016.

LofTUs, E. F. (1975). Leading questions and the eyewitness report. Cognitive Psychology, 7, 560-572.

MacCoun, R., \& KerR, N. L. (1988). Asymmetric influence in mock jury deliberation: Jurors' bias for leniency. Journal of Personality \& Social Psychology, 54, 21-33.

Maki, R. H., Weigold, A., \& ARellano, A. (2008). False memory for associated word lists in individuals and collaborating groups. Memory \& Cognition, 36, 598-603.

NEMETH, C. (1977). Interactions between jurors as a function of majority vs. unanimity decision rules. Journal of Applied Social Psychology, 7, 38-56

OHтsubo, Y. (2005). Should information be redundantly distributed among group members? Effective use of group memory in collaborative problem solving. Applied Cognitive Psychology, 19, 1219-1233. 
Pritchard, M., \& Keenan, J. (2002). Does jury deliberation really improve jurors' memories? Applied Cognitive Psychology, 16, 589-601.

ReIMER, T., \& Katsikopoulos, K. V. (2004). The use of recognition in group decision-making. Cognitive Science, 28, 1009-1029.

Reysen, M. B. (2003). The effects of social pressure on group recall. Memory \& Cognition, 31, 1163-1168.

Ruva, C., McEvoy, C., \& Bryant, J. B. (2007). Effects of pre-trial publicity and jury deliberation on juror bias and source memory errors. Applied Cognitive Psychology, 21, 45-67.

SAKS, M. J. (1977). Jury verdicts: The role of group size and social decision rule. Lexington, MA: Lexington Books.

Salerno, J. M., \& McCauley, M. R. (2009). Mock jurors' judgments about opposing scientific experts: Do cross-examination, deliberation, and need for cognition matter? American Journal of Forensic Psychology, 27, 37-60.

Sandys, M., \& Dillehay, R. C. (1995). First-ballot votes, predeliberation dispositions, and final verdicts in jury trials. Law \& Human Behavior, 19, 175-195.

Schkade, D., Sunstein, C. R., \& Kahneman, D. (2000). Deliberating about dollars: The severity shift. Columbia Law Review, 100, 11391175 .

S.E.C. v. Koenig, 557 F. 3D 736 (7th Cir. 2009).

Spanos, N. P., Dubreuil, S. C., \& Gwynn, M. I. (1991). The effects of expert testimony concerning rape on the verdicts and beliefs of mock jurors. Imagination, Cognition \& Personality, 11, 37-51.

Spellman, B. A., \& Tenney, E. R. (2010). Credible testimony in and out of court. Psychonomic Bulletin \& Review, 17, 168-173.
Tenney, E. R., MacCoun, R. J., Spellman, B. A., \& Hastie, R. (2007). Calibration trumps confidence as a basis for witness credibility. Psychological Science, 18, 46-50.

Thorley, C., \& Dewhurst, S. A. (2007). Collaborative false recall in the DRM procedure: Effects of group size and group pressure. European Journal of Cognitive Psychology, 19, 867-881.

Thorley, C., \& Dewhurst, S. A. (2009). False and veridical collaborative recognition. Memory, 17, 17-25.

Walther, E., Bless, H., Strack, F., Rackstraw, P., Wagner, D., \& Werth, L. (2002). Conformity effects in memory as a function of group size, dissenters, and uncertainty. Applied Cognitive Psychology, 16, 793-810.

Weldon, M. S., Blair, C., \& Huebsch, P. D. (2000). Group remembering: Does social loafing underlie collaborative inhibition? Journal of Experimental Psychology: Learning, Memory, \& Cognition, 26, 1568-1577.

Wheatmann, S. R., \& Shaffer, D. R. (2001). On finding for defendants who plead insanity: The crucial impact of dispositional instructions and opportunity to deliberate. Law \& Human Behavior, 25, 167-183.

Willoughiy, T., Wood, E., McDermott, C., \& McLaren, J. (2000). Enhancing learning through strategy instruction and group interaction: Is active generation of elaborations critical? Applied Cognitive Psychology, 14, 19-30.

(Manuscript received July 3, 2009;

revision accepted for publication October 8, 2009.) 